\title{
Religiusitas Gunung Merapi
}

\author{
Eko Punto Hendro \\ Program Studi Antropologi Sosial Fakultas Ilmu Budaya, Universitas Diponegoro Semarang \\ Email: eko.ipung@gmail.com
}

\begin{abstract}
The concept of 'manunggaling kawula gusti', which had developed in Java in ancient times, until now still colored the behavior of people living around Mount Merapi, which among others demanded the full devotion of the people to the Sultan and his magical companions, namely Baurekso Mount Merapi and Nyi Rara Kidul in the southern sea. Mbah Marijan and some of her descendants and followers still show loyalty, so in order to keep their Merapi they offer to the Sultan as the ruler of the human world, which is often regarded as the incarnation of Gods / Lords of the rulers of the universe. In this way they believed that their spirits would later merge with Gusti as their worship, as a form of uniting the people's physical body to the king and to rule over nature.

The purpose of this study is to find out more about the meanings contained in Mount Merapi, namely the mountain that is feared and sacred by the people of Yogyakarta, and especially those who live on the slopes of Merapi.
\end{abstract}

Key Word: Merapi, Letusan, Mikrokosmos, Kosmologi

\section{Pendahuluan}

Gunung Merapi (2968 m dpl.) sebagai salah satu gunung api aktif Indonesia telah banyak menarik perhatian masyarakat, baik karena aktivitasnya maupun keunikannya bila ditinjau dari sisi ilmiah maupun budaya. Banyak penelitian yang telah dilakukan berkaitan dengan pemantauan untuk keperluan mitigasi maupun untuk peningkatan pemahaman terhadap karakteristik Gunung Merapi itu sendiri (Andreastudi, 2006: 201-2017). Gunung Merapi adalah gunung yang terletak di perbatasan Provinsi Jawa Tengah dengan Provinsi Daerah Istimewa Yogyakarta, dan sering menunjukkan keaktifannya dengan letusan-letusan total ataupun hanya bersifat freatik. Pada bulan Mei 2018 Gunung Merapi juga mengalami letusan yang disebut dengan letusan freatik. Menurut BMKG letusan freatik yang terjadi di Gunung Merapi adalah letusan gas atau embusan asap dan material yang dipicu oleh tekanan gas yang berada di bawah permukaan.

Erupsi Gunungapi Merapi Tahun 2010 menunjukkan bahwa bencana akibat erupsi telah menyebabkan kerusakan yang sangat parah. Peristiwa ini telah menyebabkan korban lukaluka sebanyak 1.705 jiwa, terdiri dari 1.412 jiwa luka ringan dan 293 jiwa luka berat, korban meninggal sebanyak 332 jiwa serta korban yang mengalami gangguan psikologis sebanyak 4.874 jiwa (Brotopuspito dkk., 2011). Lebih jauh lagi, ia menambahkan bahwa awan panas yang terjadi pada saat erupsi Gunungapi Merapi 2010 telah menyebabkan 2.447 rumah rusak berat dan 6.472 rumah rusak sedang. Selain itu, dampak bencana sekunder erupsi Gunungapi 
Merapi berupa banjir lahar ternyata tidak kalah besar, diantaranya menyebabkan 182 kerusakan rumah di sekitar bantaran Kali Code Yogyakarta.

Seperti diketahui, selama ini letusan Merapi dikenal selalu mengarah ke barat atau barat daya. Hal ini dapat dipahami karena kawah aktif Gunung Merapi saat ini terbuka ke arah barat/barat daya, sehingga selama pertumbuhan kubah lava masih di dalam dan belum melampaui dinding kawah, maka letusan akan mengarah ke barat/barat daya. Namun bila dinding kawah telah terlampaui dan pertumbuhan kubah melimpah keluar kawah, maka kondisi ini dapat mengganggu kestabilan kubah. Hal tersebut akan mendorong longsornya kubah dan menyebabkan letusan yang terjadi mengarah ke sektor tersebut. Letusan tahun 1954-1956 yang mengarah ke utara merupakan contoh kasus tersebut. Dalam sejarah letusannya, Gunung Merapi dicirikan dengan perubahan yang sangat berarti pada tipe letusannya. Pada masa sekarang, letusan Gunung Merapi berkaitan dengan pertumbuhan dan gugurnya kubah lava, dan menghasilkan awan panas yang oleh kalangan ahli gunung api disebut sebagai tipe Merapi karena sifatnya yang khas. Tipe letusan ini juga disebut "Wedhus Gembel" oleh masyarakat di sekitar Merapi. Dalam sejarah letusannya tercatat letusan yang paling tua diketahui adalah tahun 1006. Asumsi terdahulu menyebutkan bahwa longsornya Merapi dan letusannya yang besar pada tahun 1006 telah menyebabkan perpindahan Kerajaan Hindu Mataram dari Jawa Tengah ke Jawa Timur, tetapi pernyataan ini disanggah oleh Boechari (1976), karena Mpu Sindok telah memerintah di Delta Brantas pada waktu itu (Andreastuti dkk, 2006: 201-207).

Ada beberapa hal yang menyebabkan munculnya angka letusan tahun 1006, dan yang menjadikan asumsi Bemmelen dianggap sebagai suatu kebenaran. Asal mulanya adalah dari ditemukannya Prasasti Kalkuta di India yang berangka tahun 963 Saka (1041) yang disebut juga sebagai Prasasti Pucangan. Di dalam prasasti tersebut dinyatakan bahwa telah terjadi bencana besar (pralaya) pada tahun 928 Saka (tahun 1006) akibat serangan Raja Wurawari dari Lwaram terhadap Kerajaan Mataram Hindu. Hal ini juga dikuatkan oleh Kern (1913) yang mengemukakan bahwa runtuhnya Kerajaan Mataram Hindu disebabkan oleh perang. Sementara itu Labberton (1922) mengaitkan kemungkinan penyebab runtuhnya kerajaan tersebut dengan kejadian vulkanik. Labberton (1922) dan Bemmelen (1956) juga berasumsi bahwa letusan pada tahun 1006 telah mengakibatkan perpindahan Kerajaan Mataram Hindu ke Jawa Timur. Lebih lanjut Bemmelen menghubungkan letusan tersebut dengan runtuhnya bagian puncak Merapi ke arah barat. Dijelaskan bahwa letusan besar tahun 1006 terjadi akibat pergerakan tektonik sepanjang sesar transversal yang menjadi dasar deretan Gunung Api Ungaran - Merapi. Diperkirakan gempa menyertai pergerakan tersebut dan merusak sebagian Candi Borobudur dan Mendut yang dibangun pada abad ke-9. Aktivitas tektonik ini diikuti dengan terjadinya longsoran Merapi dan letusan besar yang produk letusannya diperkirakan menutup candi-candi tersebut, merusak kerajaan Mataram Hindu Kuno di Jawa Tengah, dan membendung aliran Kali Progo. Longsoran tersebut membentuk Perbukitan Gendol yang terletak di bagian barat Merapi (Andreastuti dkk, 2006: 201-207).

Teori-teori Van Bemelen dan kawan-kawannya tersebut di atas memang banyak yang menentang, karena terdapat ketidak-sesuaian data tentang meletusnya Gunung Merapi pada tahun 1006 yang kemudian dikaitkan dengan berpindahnya kerajaan Mataram Hindu dari Jawa Tengah ke Jawa Timur. Namun demikian diperkirakan letusan-letusan Gunung Merapi pada sekitar abad ke-9 dan ke-10 Masehi memang tetap turut andil mendorong berpindahnya kerajaan Mataram Hindu dari Jawa Tengah ke Jawa Timur. Dalam hal ini yang menjadi persoalan mengapa harus pindah kerajaan itu hanya karena letusan Gunung Merapi, atau persoalan lainnya. Berpindah-pindahnya ibukota kerajaan di Jawa sejak jaman Hindu hingga jaman perkembangan Islam di masa lalu, menyebabkan beberapa sulit dilacak keberadaannya. Misalnya lokasi Medang sebagai ibukota kerajaan Mataran kuno tidak terlacak, baik yang di 
Jawa Tengah Maupun Jawa Timur. Candi Borobudur dan Candi Prambanan, kedua candi tersebut nerupakan candi yang sangat megah dan statusnya adalah warisan dunia (world heritage), namun perlu diketahui ketika diketemukan pertama kalinya kedua candi tersebut berada di tengah hutan dan sangat rusak, yang berarti ditinggalkan begitu saja oleh umatnya. Konsep pralaya seperti yang disebutkan di prasasti Pucangan yang berangka tahun 924 Saka, kiranya merupakan sebuah fakta yang menyebabkan ini semua. Waktu itu masyarakat Jawa masih sangat percaya dengan konsep keselarasan makrokosmos dan mikrokosmos. Pralaya dalam pemahaman makrokosmos adalah konsep tentang hancurnya dunia (kiamat), untuk dibangun kembali dunia yang baru. Begitulah pemahanan masyarakat tentang alam makrokosmos, dan dunianya (mikrokosmos) harus selaras dengan alam semesta (makrokosmos), maka kerajaan dan masyarakatpun akan mengalami pralaya, yang artinya harus meninggalkan tempat yang lama dan berpindah ke tempat yang baru.

Adapun tujuan penelitian ini adalah untuk mengetahui lebih jauh tentang makna-makna yang terdapat di dalam Gunung Merapi, yaitu gunung yang ditakuti dan dikeramatkan oleh masyarakat Yogyakarta, dan khususnya yang tinggal di lereng Merapi.

\section{Metode}

Tahap pertama pengumpulan data dilakukan melalui studi pustaka, yang kemudian dilanjutkan melalui observasi terhadap situs, bangunan kuno, artefak, toponim, lingkungan, cerita rakyat, mitos-mitos, ataupun elemen kota lainnya yang ada sekitar Gunung Merapi ataupun Kota Yogyakarta pada umunya. Wawancara juga dilakukan terhadap informan kunci yang mengetahui seluk beluk tentang mitos Gunung Merapi dan Keraton Yogyakarta. Datadata primer yang telah terkumpul diklasifikasikan dan dihubung-hubungkan satu dengan yang lainnya, serta dikaitkan dengan sumber-sumber pustaka sebagai bagian dari analisis data untuk mendapatkan kesimpulan ilmiah.

\section{Hasil dan Pembahasan}

\subsection{Manunggaling Kawula Gusti}

Kiranya memang masih ada sisa-sisa pemikiran masyarakat yang justru melampaui pemikiran rasional seperti di atas. Adanya keyakinan-keyakinan lokal transedental yang melukiskan bahwa Merapi bukan hanya seonggok tumpukan tanah yang di dalamnya ada magmanya, yang sewaktu-waktu bisa meletus, tetapi bak seorang tokoh gaib sakti yang sangat disegani dan dihormati, maka pihak Keraton Yogyakartapun harus menempatkan seorang 'abdi dalem' waktu itu Mbah Marijan, tidak hanya sekadar menjaga, tetapi menjadi 'sang pamomong' Gunung Merapi yang sangat ganas itu.

Apa yang dilakukan oleh Mbah Marijan sebenarnya adalah bentuk kepasrahan seorang abdi dalem atau rakyat kepada Sultan Yogyakarta yang dapat dilukiskan sebagai keturunan raja Mataram yang memiliki kekuasaan sangat besar terhadap negara maupun rakyatnya. Oleh karena itu, terhadap keinginan raja, rakyat hanya dapat pasrah dan berkata"nderek kersa dalem" (terserah kepada kehendak raja). Kekuasaan yang demikian besar itu dikatakan "wenang wisesa ing sagari" (berwenang tertinggi di seluruh negeri). Dalam cerita pewayangan, kekuasaan yang besar itu sering digambarkan sebagai "gung binatara, bau dhendha nyakrawati" (sebesar kekuasaan dewa, pemelihara hukum dan penguasa dunia (Moedjanto, 1987: 77-78).

Adanya konsep 'manunggaling kawula gusti' yang pernah berkembang di Jawa pada jaman dahulu yang sampai saat ini juga masih mewarnai perilaku masyarakat yang tinggal di 
sekitar Gunung Merapi, yang antara lain menuntut pengabdian sepenuhnya rakyat kepada Sultan dan para pendamping gaibnya yaitu Baurekso Gunung Merapi dan Nyi Rara Kidul di laut selatan. Masyarakat Merapi pada umumnya memang sudah tidak sepenuhnya mempercayai lagi konsep ini, tetapi Mbah Marijan dan beberapa keturunan dan pengikutnya masih menunjukkan "labuh labeting bhekti kawula dumateng ngarsa dalem Kanjeng Sultan Hamengkubuwana", maka dalam rangka menjaga Merapi nyawapun mereka persembahkan kepada Sultan sebagai penguasa dunia manusia, yang sering dianggap pula sebagai titisan Dewa/Tuhan penguasa alam semesta. Dengan cara ini mereka percaya bahwa arwah mereka nanti akan menyatu dengan Gusti sesembahannya, sebagai suatu bentuk penyatuan jiwa raga rakyat kepada raja maupun menguasa alam.

Masyarakat desa-desa yang terdapat di lereng Merapi bahkan percaya tentang mitos bahwa di Gunung Merapi itu ada keraton dari para makhluk halus yang menjalin persahabatan dengan Sri Sultan Hamengkubuwono dan Kanjeng Ratu Kidul di laut selatan. Dalam hal ini sebagai suatu kerajaan, Merapi juga mempunyai hubungan-hubungan dengan kerajaan lainnya, baik kerajaan manusia maupun kerajaan makhluk halus, yakni Keraton Yogyakarta dan keraton laut selatan dengan pemimpinnya Kanjeng Ratu Kidul.. Hubungan tersebut terwujud dalam bentuk antara lain upacara Labuhan dari Sultan kepada penguasa laut selatan dan Gunung Merapi, kedua keraton makhluk halus tersebut saling mengadakan kunjungan, dengan mengerahkan pasukan makhluk halus mengendarai kuda dan kereta kuda, yang sering disebut lampor, atau kunjungan kedua keraton makhluk halus tersebut ke Keraton Yogyakarta. Pasukan makhluk halus tersebut melewati sungai-sungai dengan suara gemerincing berisik terutama menjelang magrib (Triyoga, 2010: 62).

Mitos-mitos di atas sebenarnya diawali dari upaya pendiri kerajaan Mataram Panembahan Senopati dalam rangka membangun kekuatan politiknya sebagai seorang raja baru di Pajang-Mataram. Ia hanya berasal dari rakyat biasa anak Ki Ageng Pemanahan, bukan keturunan raja-raja yang berdarah biru (trahing kusumo rembesing madu). Oleh karena itu ia harus menggunakan berbagai cara untuk melegitimasi dirinya, di antaranya dengan membangun mitos tentang Nyi Roro Kidul, makhluk supranatural yang menjadi ratu di laut selatan Samudra Indonesia yang kemudian juga menjadi istrinya, serta menciptakan tokoh sepranatural lainnya yaitu Eyang Merapi penguasa Gunung Merapi. Apa yang dilakukan oleh Panembahan Senopati ini mengingatkan kepada tokoh Ken Arok yang kemudian menjadi raja pertama kerajaan Singosari. Ken Arok sebenarnya adalah orang biasa, bahkan sering dianggap pencuri. Namun ia berhasil membangun mitos melalui kitab Pararaton yang menceritakan bahwa ia adalah titisan Dewa Wisnu dan anak Dewa Brahma, maka ia harus menyelamatkan dunia dengan membunuh Akuwu Tunggul Amentung (penguasa Tumapel/Singosari) dan memperistri Ken Dedes (istri Tunggul Ametung) yang dianggap sebagai wanita padmanagara, atau wanita mulia yang akan menurunkan raja-raja (Padma Puspita, 1966).

Mitos-mitos memang sering dikaitkan dengan melegitimasikan agama atau kepercayaan, misalnya tentang cerita mitologi dewa-dewi atau cerita tentang roh-roh halus. Walaupun demikian di dunia politik, mitos juga sering untuk melegitimasikan ideologi atau kekuasaan. Baik dalam aspek agama atau politik, mitos berkaitan dengan kepercayaan tentang kebenaran agama, kepercayaan atau politik tertentu. Hal ini juga sesuai dengan pendapat Ahimsa-Putra (1995: 124) bahwa mitos sering merupakan sumber kebenaran atau alat untuk pembenaran. Sesuatu yang perlu dibenarkan melalui mitos ini dapat berupa ideologi, tradisi, kebudayaan, kepercayaan, bahkan agama. Oleh karena itu membangun mitos dapat diartikan pula sebagai membangun kepercayaan tentang kebenaran, walaupun kebenaran yang dibangun sering bukan kebenaran yang rasional. Dalam suatu interaksi sosial, simbol-simbol yang berbentuk mitos ini memang harus disampaikan melalui pesan-pesan, baik secara 
langsung oleh pemilik simbol ataupun secara tidak langsung melalui media-media sosial, benda, bangunan dan sebagainya.

Walaupun tidak ada wujudnya, masyarakat yang tinggal di lereng Gunung Merapi benar-benar percaya tentang adanya mitos keraton Merapi. Mereka sering mendengar dan melihat keraton dan bala tentaranya serta rajanya melalui mimpi-mimpi dan suara-suara. Mereka juga percaya bahwa nanti di saat meninggal akan menjadi prajurit atau masyarakat yang mengelola pertanian milik keraton Merapi seperti ketika masih hidup (Triyoga, 2010: 63). Demikian halnya masyarakat yang tinggal di pesisir selatan, juga sangat percaya dengan adanya Nyi Roro Kidul sebagai penguasa kerajaan di laut selatan. Mereka juga percaya bahwa orang-orang yang meninggal tenggelam di laut selatan memang sudah dikehendaki oleh dewi laut selatan itu. Di sebelah selatan Gunung Merapi di Desa Korijaya terdapat bukit kecil yang dinamakan Gunung Wutoh, yang dipercaya masyarakat Merapi sebagai gerbang Keraton Merapi yang menghadap ke selatan. Nama Desa Korijaya itu meungkin memang berkaitan dengan gerbang Keraton Merapi, sebab kori berarti pintu besar.

\subsection{Simbolisme Gunung Kosmis}

Sampai saat ini pandangan masyarakat Jawa dalam menyikapi kehidupannya sering diwarnai oleh pemikiran kosmis tentang jagad cilik (mikrokosmos) dan jagad gede (makrokosmos). Jagad cilik merupakan dunia kehidupan manusia yang harus selaras dengan jagad gede, yaitu alam semesta. Simpul-simpul penting alam semesta ini adalah gununggunung yang tersebar di Pulau Jawa. Pandangan kosmis ini sudah lama berkembang di Jawa, yang dilatari oleh adanya kepercayaan yang bersumber pada ajaran agama Hindu dan Budha, bahwa alam semesta ini berpusat pada gunung Mahameru (gunung Himalaya) yang dikelilingi oleh tujuh buah lautan dan tujuh buah pegunungan dalam bentuk lingkaran. Puncak gunung Mahameru merupakan tempat tinggal para dewa penguasa alam semesta dan dewa Indra sebagai rajanya yang di kitari oleh bulan, bintang, matahari dan dinaungi langit berlapis tujuh, sementara manusia dan segala kehidupan yang lain menempati lereng dan kaki gunung itu. Menurut pakar sejarah Asia Tenggara Robert Von Heine Geldern (1968), bahwa pada jaman dahulu masyarakat di kawasan Asia Tenggara sering membetuk dunianya seperti susunan alam semesta dalam bentuk kecil, yang disebut dengan membuat keselarasan atau kesejajaran antara mikro dan makrokosmos. Hal ini dilakukan semata-mata untuk menjaga keseimbangan dan ketenteraman dunia serta kesejahteraan manusia. Karena itu gambaran tentang gunung di masa lalu selalu ada di tengah-tengah masyarakat, misalnya dalam bentuk bukit-bukit kecil, candi-candi atau istana raja, sebagai pusat alam semesta dalam bentuk kecil.

Geldern juga berpendapat bahwa Angkor Thom, bekas ibukota kerajaan kuno di Kamboja yang didirikan oleh raja Jayawarman VII pada abad XII Masehi, bagan kotanya dikelilingi dinding dan parit pada bagian luarnya yang berdenah segi empat, tiap-tiap sisi dinding menghadap ke empat penjuru mata angin (cardinal point). Pada bagian tengah tiaptiap sisi dinding dijumpai gapura pintu gerbang masuk ke kota dengan menara-menara di puncaknya, gapura di sebelah timur merupakan pintu gerbang utama untuk masuk ke istana raja. Di pusat kota terdapat candi Bayon, yaitu merupakan bangunan suci Budha Mahayana dengan sebuah arca Bodisatwa Amitabha di dalamnya. Susunan kota semacam ini menggambarkan susunan alam semesta menurut doktrin Budha. Parit yang mengelilingi kota melukiskan lautan yang mengelilingi gunung Meru sedangkan candi Bayon merupakan replika gunung Meru, gunung pusat alam semesta.

Lebih lanjut Geldern (1968) mengatakan bahwa Mandalay, ibukota kerajaan Birma yang didirikan oleh raja Mindon pada tahun 1857 Masehi, sebelum Birma dijajah oleh bangsa Inggris, kota bagian dalam dari ibukota kerajaan dikelilingi dinding dan parit pada bagian 
luarnya yang berdenah segi empat. Tiap-tiap sisi dinding menghadap ke arah empat penjuru mata angin utama dan masing-masing mempunyai tiga buah gapura. Secara keseluruhan dinding keliling tersebut mempunyai mempunyai 12 buah gapura, masing-masing di hias dengan tanda-tanda zodiak. Istana raja terletak di pusat ibu kota dan di dalamnya terdapat menara berlapis tujuh tersebut menggambarkan gunung Meru, gunung pusat alam semesta. Dengan demikian jelas bahwa kota Mandalay tersebut menggambarkan kahyangan tempat tinggal dewa-dewa dengan bintang yang mengitari gunung Meru sebagai pusatnya.

Di Bali penerapan konsep kosmologi lebih jelas lagi. Bagan suatu desa atau kota kuna di Bali pada dasarnya disusun menurut konsep nawasanggah, yaitu percaya pada kekuatan magis yang bersumber pada dewa-dewa penjaga sembilan mata angin. Di Bali mata angin arah atas disebut kaja, yaitu arah ke puncak gunung, sedangkan arah bawah disebut kelod, yaitu arah kematian, sedangkan arah timur disebut kangin, yaitu arah kelahiran, dan kauh adalah arah laut. Puseh adalah titik persilangan antara garis atau jalan lurus dari kaja ke arah kelod dengan garis atau jalan lurus dari kangin ke arah kauh. Titik ini merupakan titik pusat atau titik magis dari suatu desa, pada tempat ini biasanya didirikan sebuah tugu atau arca raksasa dan merupakan tempat sesaji bagi orang yang melewatinya. Di Bali selatan arah kaja atau arah Gunung Agung berada di utara, sedangkan di Bali utara arah kaja ada di selatan. Oleh karena itu bagian tersuci dari sebuah pura ataupun puri di Bali yang biasanya ada di bagian belakang akan mengarah ke kaja atau gunung (Hendro, 2001).

Konsepsi tentang gunung ini juga dapat dijumpai pada berbagai hal, misalnya gelar rajaraja kuno seperti Sailendra, Girinata dan Girindrawandhana, adalah melukiskan tentang raja gunung. Raja-raja Mataram yang bergelar Sultan Hamengkubuwono, Susuhunan Pakubuwono dan Paku Alam, kiranya juga mengarah pada konsepsi gunung Mahameru, gunung pusat alam semesta itu. Candi-candi yang dibangun di lereng-lereng atau puncak gunung seperti candi Gedongsongo, candi Dieng, candi Sukuh dan lain-lain, karena masyarakat menganggap gunung itu suci mewakili gunung Mahameru, maka dewa-dewa akan betah bila sedang mengunjungi candi-candi tersebut. Candi itu sendiri sebenarnya juga melambangkan gunung, karena ada arca dewanya dan adanya hiasan antefik sebagai lambang gunung. Pada saat diadakan upacara Kesada oleh masyarakat Tengger yang tinggal di lereng Gunung Bromo, pemujaan gunung masih benar-benar tampak pada persajian yang dipersembahkan kepada dewa gunung. Keraton Yogyakarta dan Kraton Surakarta pada dasarnya juga melukiskan gunung pusat alam semesta karena dikelilingi oleh benteng dan parit keliling, dan di dalamnya terdapat bangunan yang bernama Ngendrakila dan Ngendrasana sebagai penggambaran dari istana Dewa Indra di puncak Mahameru. Bentuk-bentuk atap tumpang pada masjid-masjid kuno, juga pura di Bali ataupun beberapa bangunan di kraton Yogyakarta dan Surakarta, juga payung berlapis-lapis yang selalu menaungi raja saat bertahta, kiranya melukiskan langit yang berlapis-lapis yang menaungi gunung Mahameru, dan raja dianggap sebagai dewa yang bertahta dipuncaknya. Posisi raja-raja Jawa yang seperti ini, maka ia sering dianggap bukan manusia biasa dan memiliki kekuatan linuwih, serta menyebabkan di Jawa muncul kultus dewa-raja.

Dari berbagai hal di atas kiranya sangat masuk akal apabila hingga sekarang masyarakat Jawa masih mengkeramatkan gunung dan menganggapnya sebagai simbol religius. Karena itu sah-sah saja apabila sebagian dari mereka menganggap bahwa segala peristiwa yang bersangkut paut dengan gunung, seperti kejadian meletusnya gunung Merapi, semburan wedhus gembelnya, siraman abunya, guguran lava pijarnya, ataupun yang bernilai positif seperti berkah mata airnya, kesuburan tanahnya dan limpahan pasirnya, semua dianggapnya bukan hanya peristiwa alam biasa tetapi juga peristiwa budaya, bahkan suatu peristiwa religius. 


\subsection{Gunung dan Tradisi}

Orang Jawa memang sangat percaya dengan kehadiran tokoh-tokoh mistis-religius seperti itu dan sering mengkaitkannya dengan kekuatan ataupun gerakan-gerakan alam atau benda-benda keramat. Disamping itu kesaktian tokoh-tokoh tersebut sering juga dianggap sebagai tenaga gaib yang sangat berpengaruh pada kehidupan manusia. Kondisi seperti ini kiranya merupakan sisa-sisa kepercayaan kuno yang muncul pada jaman prasejarah, yang mengganggap roh-roh orang yang sudah meninggal (roh leluhur) akan menempati bagianbagian dari alam dan menggerakkannya, dan gunung atau tempat-tempat yang tinggi sering dianggap sebagai tempat yang baik untuk berkumpulnya roh-roh tersebut. Akhirnya manusia yang waktu itu kehidupannya masih sangat tergantung kepada alam tentu saja akan sangat menghormati dan memuja roh-roh tersebut, apalagi semasa hidupnya roh-roh tersebut merupakan orang sakti, orang terpandang ataupun pemuka masyarakat (Joened, 1984).

Karena sifat gunung yang ajaib dan luar biasa itu maka sekarangpun masyarakat Jawa masih sering menkeramatkannya. Gunung Merapi dan gunung Lawu sering dianggap gunung yang cukup keramat, dan banyak orang yang mendaki di kedua gunung ini dengan suatu tujuan religius, bukan rekreasi. Penunggu gunung Merapi juga dianggap memiliki hubungan khusus dengan tokoh mistis dewi penguasa laut selatan (Nyi Rara Kidul), keduanya sering saling mengunjungi melalui jalan sungai Winongo (di bagian barat kota Yogyakarta), dan penduduk di sekitar sungai itu menyebutnya rombongan makhluk mistis itu dengan sebutan Lampor. Kraton Yogyakarta dan Surakarta yang berada di antara gunung dan laut itu sering dianggap berlindung pada dua tokoh mistis itu. Oleh karena itu secara periodik kedua keraton tersebut juga mengadakan tradisi labuhan di Gunung Lawu, Merapi dan Segara Kidul, untuk menghormati tokoh-tokoh misitis penjaga alam tersebut.

Disamping itu masyarakat Jawa juga masih mengganggap gunung sebagai simbol yang sering tampak di dalam karya-karya seni, misalnya di dalam rumah-rumah, motif kain batik, ukir-ukiran, sinetron Mak Lampir, bahkan gunungan merupakan simbol utama dalam pewayangan, sebagai lambang kekuatan alam semesta. Disamping itu gunungan juga sering muncul dalam upacara tradisional garebeg di kraton Yogyakarta dan Surakarta yang dibuat dari berbagai jenis makanan dan sayuran. Masyarakat akan berebut 'ngalap berkah' ketika gunungan makanan itu disajikan untuk masyarakat yang menghendakinya. Masyarakat Jawa hingga saat ini juga masih sering mengadakan tradisi tumpengan, yaitu tradisi membuat gunung kecil dari nasi yang dilengkapi dengan lauk pauknya saat acara penting.

Pemilihan lokasi Keraton Yogyakarta menurut kitab babad dan berdasarkan pada mitos, bahwa wahyu kraton Kartasura telah berpindah tempat di hutan Beringan, yaitu suatu tempat yang pernah untuk mendirikan pasanggrahan Gerjitawati semasa Susuhunan Pakubuwono II. Pada waktu Sri Sultan Hamengkubuwono I melakukan samadi, beliau menerima wisik atau firasat bahwa tempat yang pantas untuk mendirikan kraton adalah tanah di hutan Beringan, di dekat Pacetokan. Menurut cerita mitos, hutan Beringan tersebut dijaga oleh dua ekor ular naga, yaitu bernama kyai Jaga dan kyai Jegot, maka setelah kraton Yogyakarta berdiri, kyai Jaga kemudian bertempat tinggal pada bangunan tugu, sedangkan kyai Jegot bersemayam pada bangsal Prabayeksa kraton Yogyakarta (Hendro, 2001). Lokasi Keraton Yogyakarta ini berada pada garis lurus imajiner antara Gunung Merapi dan laut selatan tempat tinggal Nyi Roro Kidul.

Pembuatan Keraton Yogyakarta selesai pada tahun 1682 Jawa dan ditandai dengan sengkalan memet berupa dua ekor naga yang saling berbelitan. Sengkalan memet tersebut dapat dibaca : Dwi Naga Rasa Tunggal, yaitu terdapat pada baturana pintu gerbang Gadung Mlati Kemandungan Selatan dan pintu gerbang Kemagangan. Pembangunan Keraton Yogyakarta kemudian diikuti dengan pembuatan benteng keliling sebagai batas wilayah 
ibukota kerajaan, pembuatan masjid Agung, dan pembuatan Tamansari sebagai tempat berekreasi Sri Sultan beserta keluarganya (Hendro, 2001).

Berkenaan dengan masalah menangani masyarakat yang tinggal di sekitar Gunung Merapi apabila terjadi letusan lagi, kiranya tidak cukup hanya dengan penjelasan rasional saja agar mereka mau mengungsi jika terjadi erupsi Merapi, tetapi juga harus dilakukan dengan penjelasan spriritual tradisional seperti yang pernah dilakukan oleh Sri Sultan Hamengku Buwono X ketika Merapi meletus dahsyat tahun 2010.

\section{Simpulan}

Dari uraian di atas dapat disimpulkan bahwa demikian dalamnya pandangan masyarakat Jawa terhadap gunung, khususnya Gunung Merapi, maka erupsinya tidak hanya dilihat sebagai peristiwa alam biasa, namun juga sebagai suatu peristiwa gaib yang dapat digambarkan sebagai seorang penguasa menuntut kesetiaan dan pengorbanan rakyatnya, dan rakyatpun akan rela menyerahkan jiwa raganya seperti yang dilakukan oleh Mbah Marijan hingga akhir hayatnya. Oleh karena itu untuk menangani masyarakat yang tinggal di sekitar Gunung Merapi, kiranya tidak cukup hanya dengan penjelasan rasional saja agar mereka mau mengungsi jika terjadi erupsi Merapi, tetapi juga harus dilakukan dengan penjelasan spriritual tradisional seperti yang pernah dilakukan oleh Sri Sultan Hamengku Buwono X ketika Merapi meletus dahsyat tahun 2010 .

Konsep gunung itu sendiri, di Jawa telah terjadi mitos yang sangat kuat tentang gunung, yang tercermin dalam bentuk tradisi maupun seni budaya Jawa yang sering ada gambaran tentang gunung. Hal ini disebabkan sejak jaman prasejarah hingga jaman Hindu Budha, gunung sangat disakralkan, dan masih berkembang sampai sekarang.

\section{Pustaka Acuan}

Ahimsa-Putra, Heddy Shri. 2001. Strukturalisme Levi-Strauss: Mitos dan Karya Sastra, Yogyakarta: Galang Press.

Andreastuti, Supriyati Dwi dkk. 2006. "Menelusuri kebenaran letusan Gunung Merapi 1006", Jurnal Geologi Indonesia, Vol. 1 No. 4 Desember 2006: 201-207

Bemmelen, R.W. van. 1956. The infl uence of geological events on human history (an example from Central Java). Verhandellingen Koningklijke Nederlands Geologische Mijnbouwkundige, Genootschap, 16, h. 20-36.

Brotopuspito (et.al). 2011. Kajian Multi Bahaya, Kerentanan, Risiko, Desain Tata Ruang Kawasan Rawan Bencana Merapi dan Implementasinya dalam Peningkatan Kapasitas dan Kesiapsiagaan Masyarakat Terhadap Bahaya Gunungapi. Laporan Penelitian. Hibah Penelitian Strategis Nasional Universitas Gadjah Mada.

Boechari, 1976. "Some consideration of the problem of the shift of Mataram's center of government from Central to East Java in the 10 th Century A.D". Bulletin of the Research Center of Archaeology of Indonesia, vol. 10, hal. 26

Geldren, Robert von Heine. 1988, "The Cosmological Fundation of Southeast Asian Architecture," Journal of The Historical Society. University of Singapore, 1967-1968, hal. 50.

Hendro, Eko Punto. 2001. Keraton Yogyakarta Dalam Balutan Hindu, Semarang: Bendera. Joened, Marwati dkk. 1984. Sejarah Nasional Indonesia, Jilid 1, Jakarta: Balai Pustaka.

Kern, H. 191. Een Oud-Javaansche steeninscriptie van Koning Er-Langga, Gravenhage : Martinus Nijhoff. 
Labberton, D.H.1922. Oud Javaansche gegevens omtrent de vulkanologie van Java. Natuurkundig, Tijdschrifts, Nederlands, Indie, 81, h. 124-158.

Padma Puspita. 1966, Pararaton. Teks Bahasa Kawi Terjemahan Bahasa Indonesia. Jogjakarta: Tamansiswa.

Triyoga, Lucas Sasongko. 2010. Merapi dan Orang Jawa, Jakarta :Gramedia Widiasarana 